\title{
Paternalistic Leadership and Its Positive Influences in Telecommuting Environment
}

\author{
Ruoyun Jiang
}

International Business School Suzhou at XJTLU, Xi'an Jiaotong-liverpool University, Suzhou City, Jiangsu Province, China, 215000

Email: Ruoyun.jiang19@student.xjtlu.edu.cn

\begin{abstract}
This paper discusses the positive influences of paternalistic leadership in the compulsory telecommuting environment caused by COVID-19. The pandemic accelerates the development of telecommuting and brings challenges and uncertainties to telecommuting workers. Paternalistic leadership is a widespread management phenomenon in China combining 3 dimensions: authoritarianism, fatherly benevolence, and moral. Since this management model will not be completely changed immediately, it will influence subordinates' responses, job performances, and psychological feelings. Based on the previous studies, this paper analyzes the functions of paternalistic leadership in China under the compulsory telecommuting situation. This study points out that paternalistic leadership helps solve the main problems of remote commuters, including role recognition and efficiency, psychological isolation, information uncertainty, and resistance to remote work.
\end{abstract}

Keywords: Paternalistic leadership, Telecommuting, COVID-19, positive function

\section{INTRODUCTION}

The existence and development of e-culture have affected the behavior of individuals and companies' operations. Telecommuting, the most obvious trend under e-culture, is usually considered as a future mode of work with positive work productivity[16]. Paternalistic leadership in China has been defined as a management style that combines 3 dimensions: authoritarianism, fatherly benevolence, and moral[5]. It is widely spread as a management phenomenon for managers, especially in state-owned enterprises and family businesses. This kind of leadership model has been rooted in traditional culture and relevant to organizational behavior, management strategy, and subordinates' response. Previous studies have shown that paternalistic leadership affect employees' outcomes, self-esteem, psychological connection, and performance[5, 20]. However, only few researches focus on the role of PL in the telecommuting area. Since the gradual development process of telecommuting is accelerated by the epidemic situation which means the change of life and work model, and the employees are facing various challenges under the evolution of managing practices and working forms. Previous researches note that telecommuters may suffer from ambiguity in role identity, psychological isolation, information uncertainty, and the feeling of resistance to telework[17, 23]. Meanwhile, paternalistic leadership will not be completely changed within a short period of time and will influence the implementation and practices of telecommuting. Therefore, the purpose of this article is to explore the positive functions of paternalistic leadership in the telecommuting environment in response to the following questions: What is the function of paternalism leadership(PL) in the compulsory telecommuting environment?

How does PL helps to solve telecommuters' problems in 4 aspects: role identification and efficiency, psychological isolation, information uncertainty, and resistance of telecommuting?

In the next part, this paper will discuss the positive influences from authoritarian style, benevolent style, and moral, these three perspectives. Since benevolent style affects individual's psychology and interpersonal relationships, the following contents will be divided into four parts: authoritarian style and employees' outcomes, benevolent style and isolation, direct connection and self-development, and PL and telecommuting inclination to respond to questions above. 


\section{DISCUSSION}

\subsection{Authoritarian Style and Employees' Outcomes}

Strict management under authoritarianism highlights the power of senior executives, which helps to avoid process chaos and improve the efficiency of the information exchange within the company. In the telecommuting environment, the traditional working model has been changed to a more decentralized and personal form which can lead to low efficiency. For instance, Bailey and Kurland pointed out that there may be confusion of job responsibilities and unsalaried working hours under telework[2]. Secondly, lacking a strong core control power in the team could cause limitations on its operations. When people work with a large amount of members in a team, people start to pay attention to the practices and distribution of others, which can cause confusion, excessive information, and ultimately reduce individual and team performance[16]. Thus, it is essential that strong management should be reinforced to maintain efficiency and ensure the quality of the outcome.

The authoritarian style is often considered as the most notable feature of paternalistic leadership which emphasizes strict social order and a strong hierarchy between manager and subordinates[7]. This kind of leadership style is widely adopted in some Asian countries, especially in China. Previous theory shows that Chinese managers tend to directly give instructions while employees prefer to accept orders from supervisors[14]. Leading with authoritarian style demands subordinates comply with the arrangement without different opinions[10]. This model reduces the time and effort spent on a meaningless repetitive discussion. Actually, in the management aspect, Wray recommends managers return to apply PL, and demonstrates the benefit of governing workers with a compliant and quiescent environment instead of making them maintain a high degree of autonomy through a case study of a manufacturing company 'Ourfirm'[21]. High supervisor power and control power of PL would not be destroyed during the telecommuting process, which means that even if they work remotely, employees can still work in a relatively arranged environment. Even though telecommuting scatters the geographical distance of people's work, managers will stress a high level of control through arranging teleconferences, and reviewing work reports, etc. In this case, PL is advantageous to make up for the problems caused by telecommuting, for example, delay of information and reduction of productivity.

\subsection{Benevolent Management Style and Isolation}

Supervisors' individual concern for their subordinates can alleviate the psychological isolation caused by telecommuting. Telecommuting usually means an independent or even isolated office environment which can cause psychological isolation especially during the COVID-19 under compulsory blockade regulations. It is defined that psychological isolation is an emotion that occurs when people are lacking support, understanding, social connection, or interaction with others[12]. Based on the previous studies, isolated telecommuters tend to hold the feeling of 'separated' from their organization. They usually mistakenly believe they are looked down upon by others and be treated unfairly in gaining resources in career development[23]. To solve these issues, the methods of maintaining psychological connection under a telecommuting environment should be considered. Leaders managing with a benevolent management style usually concern about not merely workers' individual performances but also their personal activities and prefer to show tolerance and kindness. Benevolent style requires supervisors to create an environment which has a higher mutual resource exchange level, a harmonious and strong social network, and emphasizes the need to consider giving people a balanced environment[4]. Under the influence of supervisors' benevolent behaviors, subordinates mostly show respect, commitment, and support for them[18]. Meanwhile, it constructs the psychological connection rooted in collective emotions. The inside sense of connection and being respected will bring workers' optimistic attitude and better performances. As Bandura figures out that members working under benevolent leaders tend to spend much effort to make an achievement and take a positive view towards their objects along with high collective efficacy[1]. Even in the telecommuting environment, this formed psychological mechanism will be continuously effective to relieve psychological isolation caused by telecommuting, as well. Therefore, the benevolent style in PL can help to build up a sense of belongings by establishing emotional and psychological connections among all workers within the organization.

\subsection{Direct Connection and Self-development}

Paternalism emphasizes personal relationships which can extend the benefits of direct connection in the telecommuting environment. Firstly, telecommuting has impacted the organization's traditional organizational form through changing or replacing its rights distribution among different hierarchies by using information technology[24]. This trend provides more 
opportunities for workers to directly contact their supervisors. Börekçi states that employees could communicate with upper-level managers and gain information without being noticed by others. The increases of direct contact within the company make paternalistic relationships possible[3]. Paternalism in Chinese society is associated with fatherly benevolence and moral leadership. While managing a team or an organization, managers may construct private relationships like a father and a son with employees or demonstrate their authority in control with personal family behavior or values[6]. The family-like culture within an organization could facilitate supervisors' behavior in resource distribution and subordinates' response, commitment, and loyalty. For instance, Wiesenfeld et al. show that resources such as communication, mentoring, and communication technology are being controlled by higher lever-telecommuters[22]. Those resources that can only be provided by managers and help employees to promote are usually pursued by subordinates[11]. In a benevolent style, supervisor telecommuters are willing to concern about subordinates' needs and reward them with resources indeed, which creates a positive environment for middle or lower-level employees to gain information and promote[19].

Besides, the moral leadership style emphasizes leaders' high moral standards, leading others by example and acting without selfishness[6]. Managers with a high degree of ethical care are more inclined to provide self experiences and resources selflessly to subordinates. In short, PL has further improved the resources exchange rate between supervisors and subordinates along with telecommuting which is optimistic to a company and individual itself.

\subsection{PL and Telecommuting Inclination}

Subordinates' respect for power and rights makes them tend to follow the arrangement of supervisors and they are willing to change their working mode into telecommuting style. Paternalistic leadership style impacts the power distance in China, which leads to a hierarchy relationship among company members[11]. In the paternalistic atmosphere, subordinates are willing to express respect towards supervisors, while supervisor are regarded as a 'father' in the company with their moral behavior like taking care of subordinates[8]. Smith and Hume pointed out that subordinates who are in an environment that stresses superior loyalty and obligation, tend to hold the feeling of fear when there is a disagreement with their supervisors[15]. Both cultural atmosphere and psychological mechanism in PL make employees incline themself to adopt telecommuting according to managers' requirements, even though sometimes along with reluctance. Moreover, Raghuram and Fang argue in the report that as long as employees balance the flexibility provided by telecommuting and supervisory power, telecommuting could be accepted and applied in China[17]. Actually, the supervisor plays a much important role in this process. As the study carried in China proves that subordinates' inclination of telecommuting can be high when they are certain for supervisors' strong power or while supervisors also telecommute[17]. Although telecommuters are facing various challenges in maintaining work productivity, managing unexpected changes, and overcoming problems themselves under the compulsory telecommuting environment[9], PL may help them actively adapt to the new office model instead of being compelling.

\section{CONCLUSION}

In summary, this paper explores the positive functions of PL from authoritarian style, benevolent style, and moral these three perspectives, and it also points out PL's benefits for telecommuters and their organization under compulsory telecommuting circumstances. Based on this study, paternalistic leadership can be considered as a positive management style in maintaining or improving workers' efficiency, relieving psychological isolation, supporting employees' self-development, and increasing telecommuting inclination in telecommuting environment. To maintain the efficiency of management with PL, it is suggested that managers can promote the family-liked atmosphere into the working environment, meanwhile, utilizing reward power as means of motivation. This study analyzes the positive influences of PL in the compulsory telecommuting era theoretically. The results enrich the research of telework by focusing on PL and integrating factors of cultural value and management characteristics of China.

\section{ACKNOWLEDGMENT}

I would like to express my sincere thanks to my teachers and editor. During the process of writing this report, it was Dr. Wenjing. Hou, Mr.Yajun. Ding, and Min. Han who inspire me and give suggestions in academic writing skills.

\section{REFERENCES}

[1] Bandura, A. Exercise of human agency through collective efficacy. Current Directions in Psychological Science, 9(3), 2000: 75-78.

[2] Bailey, D. E., \& Kurland, N. B. A review of telework research: Findings, new direc tions, and lessons for the study of modern work. Journal of Organizational Behavior, 23, 2002: 383-400. 
[3] Börekçi, D. Y. Paternalistic leadership style's evolution in e-culture', Istanbul University Journal of the School of Business Administration, 38(2), 2009: 103-109.

[4] Cheng, B.S., Chou, L.F., Wu, T.Y., et al. Paternalistic Leadership and Subordinate Response: Establishing a Leadership Model in Chinese Organizations, Asian Journal of Social Psychology, 2004: 7, 89-117.

[5] Chan, S. H., Huang, X., Snape, E. et al. The Janus face of paternalistic leaders: Authoritarianism, benevolence, subordinates' organization-based self-esteem, and performance. Joumal of Organizational Behavior, J. Organiz Behav. 2013: 34, 108-128.

[6] Cheng, M-Y., Wang, L. The Mediating Effect of Ethical Climate on the Relationship Between Paternalistic Leadership and Team Identification: A Team-Level Analysis in the Chinese Context. J Bus Ethics, 2015: 129, 639-654.

[7] Chen, H.-Y. \& Kao, H. S.-R. Chinese paternalistic leadership and non-Chinese subordinates' psychological health', International Journal of Human Resource Management, 20(12), 2009: 2533-2546.

[8] Chen, X. P., Eberly, M. B., Chiang, T. J., et al. Affective trust in Chinese leaders: Linking paternalistic leadership to employee performance. Journal of Management, online, 2011.

[9] Chang, Y., Chien, C. and Shen, L.-F. Telecommuting during the coronavirus pandemic: Future time orientation as a mediator between proactive coping and perceived work productivity in two cultural sample', Personality and Individual Differences. 2020.

[10] Farh, J. L., Cheng, B., Chou, L. F., et al. Authority and benevolence: employees' responses to paternalistic leadership in China', in China's Domestic Private Firms: Multidiciplinary perspectives on Management and Performance. Eds A. S. Tsui, Y. Bian, and L. Cheng (New York, NY: Sharpe), 2006: 230-260.

[11] Fu, P. P., \& Yukl, G. Perceived effectiveness of influence tactics in the United States and China. Leadership Quarterly, 11(2), 2000: 251-266.

[12] Golden, T.D., Veiga, J.F., \& Dino, R.N. The impact of professional isolation on teleworker job performance and turnover intentions: does time spent teleworking, interacting face-to-face, or having access to communication-enhancing technology matter?, Journal of Applied Psychology, Vol. 93, 2008:1412-1421.

[13] Gajendran, R. S., \& Harris, D. A. The good, the bad, and the unknown about telecommuting: Meta-analysis of psychological mediators and individual consequences. Journal of Applied Psychology, 92 (6), 2017:1524-1541.

[14] Hofstede, G. Cultural constraints in management theories. Academy of Management Executive, 7, 1993: 81-94.

[15] Smith, A., \& Hume, E. C. Linking culture and ethics: A comparison of accountants ethical belief systems in the individualism/collectivism and power distance contexts. Journal of Business Ethics, 62, 2005: 209-220.

[16] Maynard, M. T., Mathieu, J. E., Rapp, T. L., et al. Something(s) old and something(s) new: Modeling drivers of global virtual team effectiveness. Journal of Organizational Behavior, 33, 2012: 342-365.

[17] Raghuram S , Fang D . Telecommuting and the role of supervisory power in China[J]. Asia Pacific Journal of Management, 2014, 31(2):523-547.

[18] Singh, P., \& Bhandarker, A. Corporate success and transformational leadership. New Delhi: Wiley Eastern, 1990.

[19] Snell, R. S., Wong, M. M., Chak, A. M., et al. Representational predicaments at work: How they are experienced and why they may happen. Asia Pacific Journal of Management, 30(1), 2013: 251-279.

[20] Schaubroeck, J. M., Shen, Y., \& Chong, S. A dual-stage moderated mediation model linking authoritarian leadership to follower outcomes. Journal of Applied Psychology, 102(2), 2017:203-214.

[21] Wray, D. Paternalism and its discontents: a case study'. Work, Employment and Society, 10, 4, 1996: 701-15.

[22] Wiesenfeld, B., Raghuram, S., \& Garud, R. Managers in a virtual context: The experience of self threat and its effects on virtual work organizations. In C. L. Cooper \& D. M. Rousseau (Eds.). Trends in Organizational Behavior, 1999: 31-43.

[23] Wang, W., Albert, L., \& Sun, Q. Employee isolation and telecommuter organizational commitment. Employee Relations, ISSN: 0142-5455, 2020: 609-625.

[24] Zammuto, R. F., Griffith, T. L., Majchrzak, A., et al. Information technology and the changing fabric of organization. Organization Science, 18(5), 2007 : 749-762. 